as well as positive sources of error. When the latterthe Idols-have been removed, it is time to provide aids to supplement the former. The senses have two defects. In the first place, they are sensitive only for a small range of stimuli. Secondly, their deliveries are always infected by subjectivity; they tell us of things, not as they are in Nature, but as they affect a particular organism at a particular time and place. The first kind of defect can be remedied to a large extent by suitable instruments. The second can be remedied by comparison between different senses of the same observer, or the same sense of different observers. Bacon holds that the deliveries of the senses, when properly compared, criticised, and neutralised, are trustworthy, and are the only possible foundation of science.

When the mind has been thus purified and helped, it is time to give it directions for collecting a complete natural history. Bacon recognised that the actual collection of such a natural history would be a work which would take much time, trouble, and expense, and in which many men would have to co-operate. $\mathrm{He}$ hoped to secure such co-operation, and to confine himself to giving directions and to completing the logical principles for interpreting and generalising the facts. Unfortunately he received no help either in money or in kind, and so he was forced to collect his data for himself, a task for which he was obviously ill-fitted.

Bacon's scheme for a complete natural history was as follows. It was to consist of an account of the normal course of Nature, of abnormalities spontaneousiy produced in the course of Nature, and of results deliberately produced by the interference of man. Bacon attached very great importance to deliberate experiment as compared with passive observation. He also attached great weight to the observation of spontaneous abnormalities. They set us free from prejudices, and they suggest means of producing rew substances and changes artificially. Bacon explicitly recognised that there is no fundamental distinction between natural and artificial products. In the history of the normal course of Nature we are not to neglect what is commonplace or to omit what is filthy. The method of selection is to be the following. Data are to be chosen, not for their intrinsic interest or for their immediate practical usefulness, but for their capacity to throw light on the structure and laws of Nature. Bacon's views on practical applications in science are admirably just. On one hand, he regards the practical control of Nature as the ultimate end of science, and ability to produce observable results as the ultimate test of any scientific theory. On the other hand, he fully recognises that Nature can be controlled practically only by being understood theoretically; and he constantly asserts that to aim directly at particular applications is fatal to pure science and short-sighted even from the point of view of practice.

Bacon gives rules for recording and arranging the data of the natural history when they have been collected. The following are the most interesting. All data that can be accurately measured should have their values recorded; where accurate measurement is impossible, upper and lower limits should be assigned. All difficult experiments must be fully and carefully described, so that others can criticise and, if necessary, repeat them. The data must be tabulated and classified from the very first. But we must recognise that at first the natural history will almost certainly contain some alleged facts which are not genuine, and that our first classifications will be partly inappropriate. If, however, the bulk of the data recorded are genuine facts, they will suffice to establish the general laws and structure of Nature ; and, in the light of this, the few errors will stand out as anomalies and can be reinvestigated and corrected. Similarly, it will be necessary to return to the natural history again and again as our knowledge of the general laws and structure grows, and to reclassify the data in the light of this increased knowledge. Probably a work like Beilstein's "Dictionary of Organic Chemistry" would be a good example of what Bacon meant by a natural history. Yet of course the classification of compounds within this dictionary depends entirely on chemical theory, whilst Bacon wanted his natural history to be as free from theory as possible. The solution of this apparent contradiction is that the natural history and the theories induced from it act reciprocally and successively on each other. The first and crudest form of the natural history involves the minimun of theory and gives rise to the crudest inductions. The natural history is now corrected and reclassified in terms of these inductions. It thus imbibes an additional dose of theory, and becomes the basis for more accurate inductions which in turn react on itself. (To be continued.)

\title{
Antarctic Weather.
}

$\mathrm{T}^{\mathrm{H}}$ E recent publication of Dr. Simpson's interesting Halley Lecture of 1923 focusses attention once more on the little-known causes which are responsible for the weather of the. Antarctic continent. In his lecture Dr. Simpson dealt particularly with the meteorological conditions as they affected adversely Capt. Scott's journey to and from the South Pole, and justified Scott's own view that the conditions on the last stage of the return journey were such as could not have been foreseen. This impossibility of forecasting weather conditions is of course shared by the Antarctic continent with many other regions of the earth, but there is some reason for believing that the contrasts in weather conditions from year to year and from day to day are very pronounced, at least in the region of South Victoria Land, to which area these remarks chiefly refer.

A visitor's first sight of the still active volcano forming the summit of the ice-clad Ross Island is indeed prophetic of the contrasts he will later experience; he will be no less surprised to discover that the continent, roughly circular and of radius some $\mathbf{r} 200$ miles, is almost entirely covered with ice and snow, though it could, so far as precipitation is concerned, be classed almost as a desert. The general surface circulation is anticyclonic, the air flowing outward from the continent with an easterly component due to the earth's rotation. Superposed on the normal distribution of wind velocities

NO. 2970, VOL. I I 8 ] 
appropriate to the anticyclone is a fairly frequent and high south-easterly wind. These blizzards are inclined to commence more suddenly in winter than in summer, and to occur more frequently during the darker months. On the floating Ross Barrier the yearly excess of precipitation over loss from the surface is only some 8 in. of solid ice, on the average. On the plateau, the net gain to the surface is probably a good deal less than this, the gain being balanced approximately by the downward flow of ice in glaciers of various types. The ice covering differs from that in other regions of the globe in that it does not melt appreciably on land and often pushes a floating 'tongue' for many miles into the sea before a point is reached where melting can set a limit to its advance. Practically the whole of the small snowfall must be formed during blizzards; it is also during blizzards that evaporation from an ice surface is a maximum, at least in the winter months.

Though possibly not in the most logical manner, this leads us to consideration of the blizzard of the western Ross Barrier-that blight of English expeditions. On account of its geographical position and the lower temperature of the Barrier, the pressure over it is higher than over the Ross Sea. This causes a preponderance of surface air-flow from the south and east, on the western side of the Barrier; any increase of this pressure difference-for example, in the form of a moving pressure wave-causes a blizzard. Simpson has indeed showed that blizzards occurred in McMurdo Sound, which lies at the north-west corner of the Barrier, when the pressure difference between that place and Amundsen's headquarters, at the north-east corner, increased ; high northerly and light southerly winds, or calms, occurring when the pressure difference decreased. Even when no snow is being formed, the air during a blizzard is filled with vast quantities of loose snow scooped up from the surface, and, at the same time, the temperature generally rises. These characteristics and the gustiness of the blizzard suggest a thorough mixing of the cold surface air with warmer air above it. Blizzards may be of short duration or may last a week or longer; that during which Scott and his party perished lasted for at least ten days. The position of a party storm-bound for many days in a tiny tent is not particularly comfortable, especially when the sun is low, and one can readily imagine the earnest-even fierce-and interminable discussions which accompany the blizzard : Is a wind of 60 miles an hour and a temperature of $-30^{\circ} \mathrm{F}$. worse or better than a wind of 50 miles and a temperature of $-40^{\circ} \mathrm{F}$.? How much cream goes to the making of cream cheese? Is it better to sleep with the fur side of the sleeping bag inside, or with the skin side inside?

The western barrier blizzard occurs most frequently in the winter and the adjacent months. To appreciate the reason for this, it is necessary to consider the intensity of radiation to and from the surface, bearing in mind that air receives or loses heat chiefly by contact with the surface. On the snow-covered Barrier, the surface is peculiarly sensitive to radiation on account of the low specific heat and low heat conductivity of the loose snow covering, in comparison with the corresponding constants for the sea which bounds it on the north. Over the sea, convection is operative, and there is a normal temperature gradient in the air above it. The same is true over the Barrier when the inward directed radiation is sufficiently intense, the surface temperature being, however, naturally unable to rise above freezing point. When outward directed radiation predominates, the snow surface rapidly cools and an inverse temperature gradient is established in the air above, provided the horizontal air flow is not too great. This results in a large daily amplitude of temperature on the Barrier-a variation which is almost exactly in phase with the sun's altitude. In appropriate conditions, a mean amplitude of $20^{\circ} \mathrm{F}$., corresponding to a variation in the sun's altitude from $10^{\circ}$ to $30^{\circ}$ above the horizon, has been measured, a range which equals the mean daily amplitude in India, where the sun nearly reaches the zenith and is below the horizon for almost twelve hours.

Due to the same causes, the yearly variation of temperature lags only eight days behind the sun. For the summer $191 \mathrm{I}-\mathrm{rg} \mathbf{2}$ the mean temperature on the plateau for the midsummer month was $-9^{\circ} \mathrm{F}$., with a mean temperature of $-\mathrm{I} 9^{\circ} \mathrm{F}$. for the following month. These figures are suggestiye of what is likely to occur on the plateau in the depth of winter when the temperatures on the Ross Barrier, which is almost at sealevel, fall at least to the minus seventies. Except in summer, the mean temperature of the Barrier is fixed largely by the frequency of the southerly blizzards, each of which causes a rise in temperature. The low Barrier temperatures, which played so great a part in the disaster to Scott's party, were such as could be expected to occur occasionally; what was entirely unexpected was the length of the cold spell, or, in other words, the unusual paucity of blizzards in late February and March. When the blizzard did come, it was of unusual duration and came at a critical time, when the party was within eleven miles of One Ton Depôt.

March and April are probably critical months, since the formation of a permanent winter ice covering in McMurdo Sound seems to be conditioned largely by its ability to reach a sufficient thickness between blizzards, before the winter weather sets in.

Travel on the Barrier at a time when the sun is setting, or has set for the winter, is indeed an unpleasant business, and considerable advantage is gained by choosing a time for the commencement of a long journey so that Christmas falls practically in the middle of the period. Apart from the necessity of avoiding the bad weather of the autumn, one should strive by this means to avoid the bad sledging surfaces associated with low temperatures. We have no quantitative information about the relative friction at temperatures about and far below $0^{\circ} \mathrm{F}$., or in fine and coarse-grained snow, but the differences are known to be very important, and the great wear of the sledge runners is quite sufficient indication of the increased friction at really low temperatures. On cold, freshly-fallen snow of a 'floury' consistency the effort of hauling is so great that one has the feeling that the friction is a friction, not between snow and runner, but between adjacent snow grains.

Much more data are required before the weather of the Antarctic can be known in more than its broad outlines-data which can only be gathered by concerted

$$
\text { NO. 2970, VOL. II } 8 \text { ] }
$$


action and by the permanent occupation of temporary observatories. The present poverty of the country is such that no well-found expedition is likely to be launched in the near future, but the time will come when further information will be urgently required, and this will be the time for insisting on the im- portance of such conditions as will obtain the fullest scientific value for money expended. It is hoped that the Scott Polar Research Institute, the formal inauguration of which has recently taken place at Cambridge, will have some influence in determining questions of this nature.
C. S. W.

\section{Obituary.}

Prof. F. W. Gamble, F.R.S. A DISTINGUISHED English zoologist, a remarkably A fine teacher and a man of a singular charm of character, has been lost to science by the death, on September 14, of Prof. Frederick William Gamble, Mason professor of zoology and comparative anatomy in the University of Birmingham. He was born in Manchester on July I3, I869, and was educated at the Manchester Grammar School and at the Owens College. At the College he came under the influence of the late Prof. A. Milnes Marshall, and catching his enthusiasm for the study of animal morphology, devoted himself to zoological studies. After taking his degree with firstclass honours in the newly established Victoria University and gaining the Bishop Berkeley research fellowship, he went abroad and studied for a time in the University of Leipzig. The first two papers from his pen, one on our rare British Nudibranchs, published in $\mathrm{I} 892$, and the other on the British marine Turbellaria, published in 1893 , were descriptive and systematic in character, but already they showed evidence of the tendency of his mind towards the experimental side of the subject.

After a short period as a junior demonstrator, Gamble was made lecturer and senior demonstrator in zoology in the University of Manchester, and in I 896 he completed his account of the flatworms and Mesozoa for the "Cambridge Natural History," a most interesting and valuable contribution to that excellent text-book. It was about this time that the lug-worm (Arenicola) was introduced as a type in the schedule for the first M.B. examination of the Victoria University; and finding from laboratory experience that the current accounts of the structure of this worm were inadequate and in many respects inaccurate, Gamble and his colleague J. H. Ashworth prepared and published in the Quarterly Journal of Microscopical Science a very careful and elaborate description of its anatomy. 'This study led to the important discoveries by Ashworth, at a later date, of the structure and function of the giant nerve cells and nerve fibres of the Polychæta.

While the work on Arenicola was still in progress, Gamble's interest was attracted to the colour changes in the 'Phantom' shrimp Hippolyte varians, and, working now in partnership with a colleague in the botanical department, Mr. (now Sir Frederick) Keeble, a series of experiments were made at the fisheries' station at Piel which led to very interesting and remarkable results. The discovery of a blue nocturnal phase in all the colour varieties of this shrimp was in itself a novel and startling fact, but when the researches were extended to the higher forms of Crustacea, many other very important systematic and physiological results were obtained. In I 903 another paper by the same authors, working on the coast of France, appeared in the Quarterly Journal of Microscopical Science, on the bionomics and physiology of the remarkable turbellarian worm Convoluta roscoffensis, in which it was proved that the green corpuscles of the Convoluta represent a phase in the life-history of a flagellate organism allied to the genus Carteria, and that this organism infects the eggs after they are laid. It is not an exaggeration to say that this study in symbiosis has become one of the important classics of the subject. It is frequently referred to by later writers as the chief authoritative statement on the physiological relationship of host and guest.

It is not possible in this place to refer in detail to other scientific work Gamble did when this partnership was dissolved. It was characterised by the same love of the experimental method, accurate observation, and cautious deduction that was shown in his earlier writings.

With all his love for scientific research Gamble combined all the great qualities of a conscientious and explicit teacher. He spared no pains to make his lectures and demonstrations effective, with the result that he earned the respect and gratitude of a large number of his pupils and colleagues. In the two admirable little books which he published, "Animal Life" and "The Animal World," he has left some indication of the way in which he presented the problems of biology to an unscientific audience; and his account of the Radiolaria in Lankester's "Treatise on Zoology " shows his power of mastering the literature of a large subject and presenting the substance of it in an intelligible way to the more advanced student.

By the death of Gamble many of us have lost a most sincere and devoted friend. His quiet, modest manner, his constant readiness to help his colleagues and his pupils, and his unblemished character, endeared him to a wide circle of friends and acquaintances. He was elected a fellow of the Royal Society in 1907 and appointed professor of zoology in the University of Birmingham in rgog. He was president of Section D of the British Association at the Toronto meeting in 1924, where he delivered a very interesting address dealing principally with the question of the metabolic gradients.

Gamble married, in 1904, Ellen, daughter of the late Rev. J. M. Bamford, of Arnside, who survives him. He left no children.

\section{WE regret to announce the following deaths :}

Prof. Rudolf Eucken, from I874 until 1920 professor of philosophy in the University of Jena, and author of many works on philosophy, on September I4, at eighty years of age.

Dr. Paul Kammerer, of the Biologische Versuchsanstalt, Vienna, known for his experimental work on the inheritance of acquired characters in amphibia, on September 23, aged forty-five years.

$$
\text { NO. 2970, VOL. I I 8] }
$$

